\title{
Mutations of Two Major Coagulation Factors Are Not Associated with Male Infertility
}

\author{
CHRISTOS YAPIJAKIS ${ }^{1,2}$, NIKOS PACHIS ${ }^{1}$, DIMITRIS AVGOUSTIDIS ${ }^{3}$, \\ MARY ADAMOPOULOU ${ }^{1}$ and ZOE SEREFOGLOU ${ }^{1}$ \\ ${ }^{1}$ Department of Molecular Genetics, Cephalogenetics Diagnostic Center, Athens, Greece; \\ ${ }^{2}$ First Department of Neurology, University of Athens Medical School, Eginition Hospital, Athens, Greece; \\ ${ }^{3}$ Department of Oral and Maxillofacial Surgery, Evangelismos General Hospital, Athens, Greece
}

\begin{abstract}
Background: Thrombophilia-related mutations, such as coagulation factor $V$ Leiden and factor II (G20210A), have been associated with female infertility due to spontaneous abortions during pregnancy. The possible role of mutations of these two factors in male infertility has not been studied to date. Materials and Methods: A total of 208 unrelated Greek men were investigated, including 108 infertile men with idiopathic oligozoospermia, azoospermia, and oligozoospermia of various etiologies, as well as 100 fertile male controls. DNA extracted from participants' sperm or blood was analyzed for factor $V$ Leiden and factor II G20210A mutations. Results: There were no significant differences in factor $V$ and factor II genotypes between infertile men and normal controls. Conclusion: An association of the two common thrombophilia-related mutations with male infertility was not observed in this preliminary study.
\end{abstract}

Thrombophilia (OMIM 188050) is a multi-factor predisposition for thrombosis, an innate incident of hypercoagulation due to several genetic and other factors. Patients with thrombophilia often suffer from brain stroke, myocardial infarction, and deep vein thrombosis (1). Female patients in particular may experience obstetrical complications, as well as spontaneous abortions, during pregnancy (2-4). Thrombophilia affects up to $10-15 \%$ of individuals on a global scale (2).

One of the most common inherited defects in Europeans causing thrombophilia is the coagulation factor V Leiden

Correspondence to: Christos Yapijakis, DMD, MS, Ph.D., First Department of Neurology, University of Athens Medical School, Eginition Hospital, Vas Sofias 74, Athens 11528, Greece. Tel: +30 2107289125, Fax: +30 2109402766, e-mail cyapi@med.uoa.gr

Key Words: Male infertility, coagulation factors, mutations. mutation (G1691A) (5). A plasma glycoprotein is activated by thrombin/factor $\mathrm{Xa}$ and converted into factor Va when encoded by the factor $\mathrm{V}$ gene. As a result of the mutation, a cleavage site of the anticoagulant-activated protein $\mathrm{C}$ in factor $\mathrm{Va}$ is destroyed. This mutation is responsible for 20 $25 \%$ of isolated thrombotic events and for $40-45 \%$ of cases of familial thrombophilia and fetal loss $(3,4)$. Several studies have reported a high frequency of factor $\mathrm{V}$ Leiden mutation in Caucasians (1.5-8.8\%), while in other populations, the mutation is rare $(2,6)$.

Another common defect is G20210A mutation in the 3' untranslated region of the coagulation factor II (prothrombin) gene $(2,7)$. Factor II is a plasma glycoprotein which is activated to thrombin by factors Xa and Va. The G20210A mutation is related to elevated plasma level of factor II, and increased risk of venous thrombosis (7). The G20210A mutation has an allelic frequency of 1.3-4.5\% in Caucasian populations $(6,8)$.

Both common coagulation factor mutations (Leiden and G20210A) have been associated with spontaneous abortions during pregnancy and female infertility (1-4). While male infertility accounts for about half of infertility cases that characterize $15-20 \%$ of couples (9), to our knowledge there is no report of testing of the two major coagulation factor mutations in infertile men. Another common thrombophiliacausing mutation, C677T, in the methylene-tetrahydrofolate reductase $(M T H F R)$ gene has been associated with both female and male infertility (10-12).

Male infertility is characterized by decreased number of spermatozoa (oligozoospermia) or their complete absence in the ejaculate (azoospermia) (13). A variety of factors may lead to aberrant spermatogenesis including chromosomal aberrations, Y-chromosome microdeletions, gene defects, hormonal abnormalities including diabetes, genital infection, as well as chemical and physical agents (14).

In order to study the possible association between thrombophilia and oligozoospermia or azoospermia, we 
investigated the common thrombosis-causing defects factor V Leiden and factor II G20210A in infertile men.

\section{Materials and Methods}

Study group. The research was performed on stored DNA samples isolated from spermatozoa and blood. A total of 208 unrelated men of Greek origin were investigated in this study: 108 men with fertility problems and 100 fertile men who served as normal controls. A collection of samples of semen and blood was conducted in the years 2002-2004 at the Department of Fertility, Bioerevna Diagnostic Center (Athens, Greece), after informed consent (14). All men participating had a full clinical, hormonal and semen evaluation and were considered to be infertile or normal according to the WHO recommendations of 1999 (13). Semen analysis was performed on at least two separate occasions and mean final values were calculated for each man participating. All participants had a detailed phenotypic profile with normal karyotype, as shown by standard G-banding cytogenetic analysis of white blood cells. The group of fertile controls had normal values of sperm count $\geq 20 \times 10^{6} \mathrm{ml}^{-1}$, sperm volume $>1.5 \mathrm{ml}$, $>50 \%$ motility and $>40 \%$ normal morphology. Individuals who were infertile were divided into three subgroups: group A $(n=28)$ included men with idiopathic moderate oligozoospermia $\left(<20 \times 10^{6} \mathrm{ml}^{-1}\right)$; group B $(\mathrm{n}=42)$ men with azoospermia or idiopathic severe oligozoospermia $\left(<5 \times 10^{6} \mathrm{ml}^{-1}\right)$; and group $\mathrm{C}$ $(n=38)$ with azoospermia or oligozoospermia of various known etiologies (including varicocele, cryptorchidism, hypospadias, infection of accessory glands and homozygous form of betathalassemia).

Molecular analysis. Total DNA was extracted from sperm or blood with the use of the Nucleon ${ }^{\mathrm{R}}$ DNA Isolation kit (Macherey-Nagel, Dúren, Germany) according to the manufacturer's instructions. Genomic DNA from four azoospermic individuals with null sperm count (group B) was isolated from blood samples. Molecular analysis for the Leiden mutation in the factor $\mathrm{V}$ gene and the G20210A mutation in the factor II gene was conducted as previously described (15). It involved amplification with polymerase chain reaction (PCR) method and digestion with restriction endonuclease TaqI. The resulting DNA fragments were separated by size with agarose gel electrophoresis. The presence of each mutation results in the alteration of a TaqI recognition site, therefore, the PCR product is not cleaved by the enzyme. After TaqI treatment, the PCR product of $175 \mathrm{bp}$ for factor $\mathrm{V}$ and of $118 \mathrm{bp}$ for factor II is seen on electrophoresis as two fragments $(157+18$ bp and $98+10 \mathrm{bp}$, respectively) when a normal allele is present, and intact when a mutant allele exists.

Statistical analysis. All statistical analyses were performed using the SAS ${ }^{\circledR}$ software (version 9.0; SAS Institute Inc., Cary, NC, USA). The observed genotypic and allelic frequencies of the control group were tested for compliance with Hardy-Weinberg equilibrium. The frequencies of alleles and genotypes found in the whole cohort or groups of infertile patients were compared to the respective frequencies of the control group using the Fisher's exact test and age-adjusted odds ratios. The Maentel-Haenzel method was used for the calculation of all odds ratios with a $95 \%$ confidence interval (CI). The accepted significance level was set at $p<0.05$.

\section{Results}

The genotypes of factor $\mathrm{V}$ and II genes in the control group were in Hardy-Weinberg equilibrium, therefore they represented a valid sample of the general Greek population. There were no statistically significant differences in factor $\mathrm{V}$ genotypes between the total cohort of infertile men (five heterozygotes and one Leiden homozygote out of 108) and the normal controls (five heterozygotes out of 100). Furthermore, there was no significant difference of the factor II genotypes in infertile patients (one heterozygote out of 108) compared to normal controls (four heterozygotes out of 100).

The 108 infertile men investigated for both factors II and $\mathrm{V}$ were divided into three groups according to their sperm count and defect etiology. Genotypes of patients in three different groups did not differ statistically from those of the normal controls (Table I).

\section{Discussion}

There is accumulating evidence that there is a connection between thrombophilia factor MTHFR and infertility of both men and women $(1,3,10-12,16-18)$. In females, the C677T mutation in the MTHFR gene greatly increases the risk of miscarriage $(1,3,11,16-18)$. As far as males with azoospermia are concerned, there is a high prevalence of the MTHFR C677T mutation in comparison to fertile controls $(19,20)$.

To our knowledge, this is the first study to investigate the possible association between other common thrombophiliarelated factors and azoospermia or oligozoospermia. There was only one other study conducted in male partners of subfertile couples regardless of their spermatogenesis status, which reported that factor $\mathrm{V}$ Leiden carriers had higher total sperm counts and total motile sperm counts than noncarriers. However, these findings were not statistically significant (21).

In the present study, no statistically significant differences in factor $\mathrm{V}$ and factor II genotypes were observed between the whole cohort of infertile men and normal controls. Since the number of patients investigated in this study is modest, this first observation of a lack of association of these mutations and severe male infertility needs confirmation by larger studies.

\section{References}

1 Liatsikos SA, Tsikouras P, Manav B, Csorba R, von Tempelhoff GF and Galazios G: Inherited thrombophilia and reproductive disorders. J Turk Ger Gynecol Assoc 17: 45-50, 2016.

2 Gathof BS, Picker SM and Rojo J: Epidemiology, etiology and diagnosis of venous thrombosis. Eur J Med Res 9: 95-103, 2004.

3 Dilley A, Austin H, El-Jamil M Hooper WC, Barnhart E, Evatt L, Sullivan PS, Ellingsen D, Patterson-Barnett A, Eller D, 


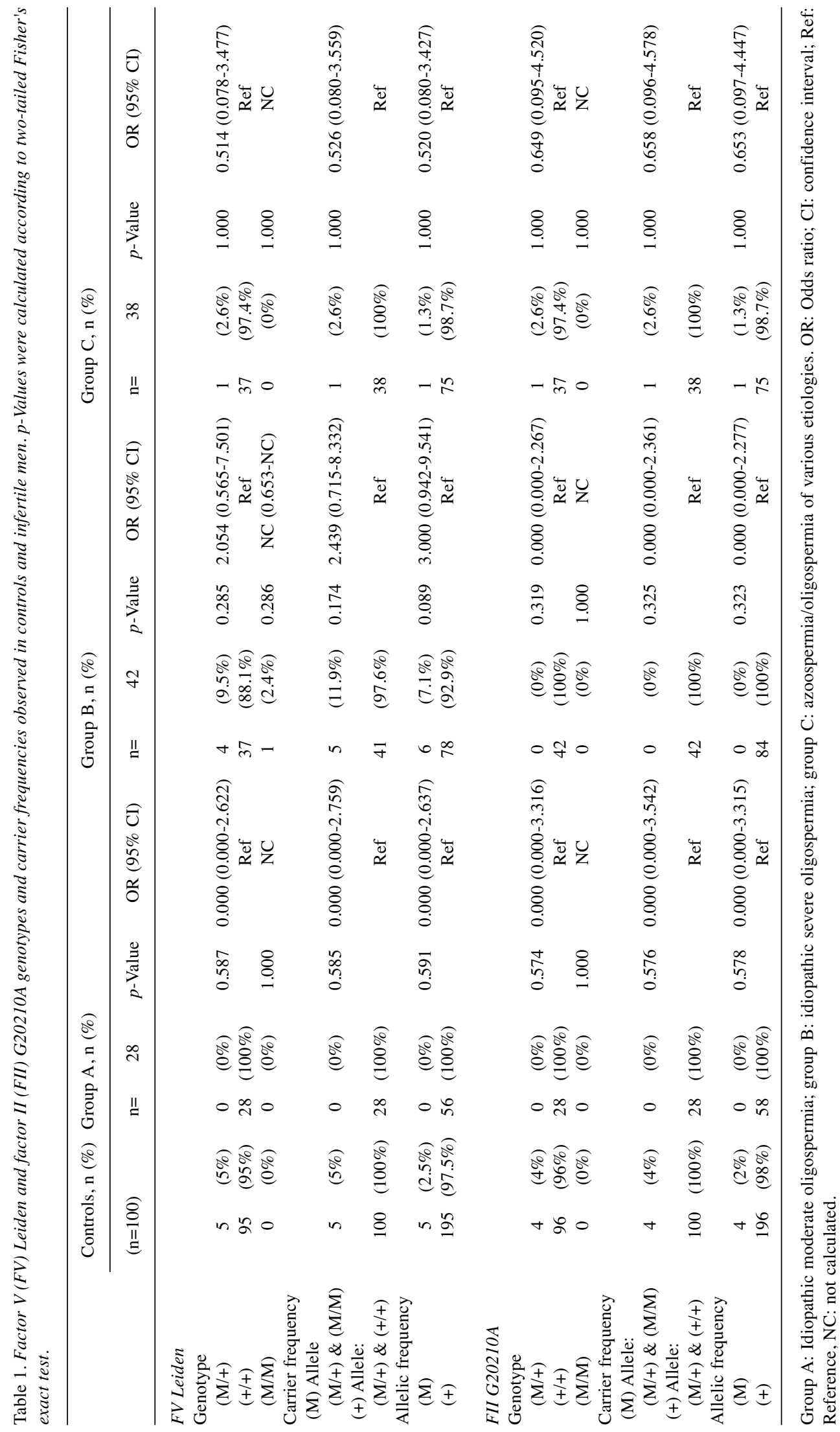


Randall $\mathrm{H}$ and Philipp C: Genetic factors associated with thrombosis in pregnancy in a United States population. Am J Obstet Gynecol 183: 1271-1277, 2000.

4 Coppage KH, Hinton AC, Moldenhauer J, Kovilam O, Barton JR and Sibai BM: Maternal and perinatal outcome in women with a history of stroke. Am J Obstet Gynecol 190: 1331-1334, 2004.

5 Bertina RM, Koeleman BP, Koster T, Rosendaal FR, Dirven RJ, de Ronde H, van der Velden PA and Reitsma PH: Mutation in blood coagulation factor $\mathrm{V}$ associated with resistance to activated protein C. Nature 369: 64-67, 1994.

6 Yapijakis C, Serefoglou Z, Nixon AM, Vylliotis A, Ragos V and Vairaktaris E: Prevalence of thrombosis-related DNA polymorphisms in a healthy Greek population. In Vivo 26: 10951101, 2012.

7 Poort SR, Rosendaal FR, Reitsma PH and Bertina RM: A common genetic variation in the 3'-untranslated region of the prothrombin gene is associated with elevated plasma prothrombin levels and an increase in venous thrombosis. Blood 88: 3698-3703, 1996.

8 Hessner MJ, Luhm RA, Pearson SL, Endean DJ, Friedman KD and Montgomery RR: Prevalence of prothrombin G20210A, factor V G1691A (Leiden), and methylenetetrahydrofolate reductase (MTHFR) C677T in seven different populations determined by multiplex allele-specific PCR. Thromb Haemost 81: 733-738, 1999.

9 Hekmatdoost A, Lakpour N and Sadegni MS: Sperm chromatin integrity: etiologies and mechanisma of abnormality, assays, clinical importance, preventing and repairing damage. Avicenna J Med Biotechnol 1: 147-160, 2009.

10 Yang Y, Luo YY, Wu S, Tang YD, Rao XD, Xiong L, Tan M, Deng MZ and Liu H: Association between C677T and A1298C polymorphisms of the MTHFR gene and risk of male infertility: a meta-analysis. Genet Mol Res 15(2): doi: 10.4238/ gmr.15027631, 2016.

11 Gulino FA, Capriglione S, Fauzia M, Di Gregorio LM, Di Stefano A, Musmeci G, Angioli R and Palumbo MA: Which are the most common thrombophilic genetic nucleotide polymorphisms in infertile women undergoing an IVF cycle? Gynecol Endocrinol 25: 1-4, 2016.

12 Zhu X, Liu Z, Zhang M, Gong R, Xu Y and Wang B: Association of the methylenetetrahydrofolate reductase gene C677T polymorphism with the risk of male infertility: a metaanalysis. Ren Fail 38: 185-193, 2016.
13 European Association of Urology (EAU): Guidelines on Male Infertility. p 15, 2007.

14 Yapijakis C, Serefoglou Z, Papadimitriou K and Makrinou E: High frequency of TTTY2-like gene-related deletions in patients with idiopathic oligozoospermia and azoospermia. Andrologia 47: 536-544. 2015.

15 Yapijakis C, Serefoglou Z and Voumvourakis C: Common gene polymorphisms associated with thrombophilia. In: Thrombosis, Atherosclerosis and Atherothrombosis - New Insights and Experimental Protocols, Božič-Mijovski M. (Ed.), InTech Publications, 2015.

16 Casarini L and Simoni M: Gene polymorphisms in female reproduction. Methods Mol Biol 1154: 75-90, 2014.

$17 \mathrm{Zhu}$ L: Polymorphisms in the methylene tetrahydrofolate reductase and methionine synthase reductase genes and their correlation with unexplained recurrent spontaneous abortion susceptibility. Genet Mol Res 14: 8500-8508, 2015.

18 Isaoglu U, Ulug P, Delibas IB, Yilmaz M, Kumtepe Y, Dogan H and Tasdemir $\mathrm{S}$ : The association between inherited thrombophilia and recurrent pregnancy loss in Turkish women. Clin Exp Obstet Gynecol 41: 177-181, 2014.

19 Gava MM, Chagas Ede O, Bianco B, Christofolini DM, Pompeo AC, Glina S and Barbosa CP: Methylenetetrahydrofolate reductase polymorphisms are related to male infertility in Brazilian men. Genet Test Mol Biomarkers 15: 153-157, 2011.

20 Weiner AS, Boyarskikh UA, Voronina EN, Tupikin AE, Korolkova OV, Morozov IV and Filipenko ML: Polymorphisms in folate-metabolizing genes and risk of idiopathic male infertility: a study on a Russian population and a meta-analysis. Fertil Steril 101: 87-94, 2014.

21 Cohn DM, Repping S, Büller HR, Meijers JC and Middeldorp S: Increased sperm count may account for high population frequency of factor V Leiden. J Thromb Haemost 8: 513-516, 2010 .
Received July 5, 2016

Revised July 25, 2016

Accepted July 29, 2016 